DOI: $10.1007 / \mathrm{s} 11631-007-0214-4$

\title{
REE/trace element characteristics of sandstone-type uranium deposits in the Ordos Basin*
}

LING Mingxing (凌明星) $)^{1,2}$, YANG Xiaoyong (杨晓勇) $)^{1,2 * *}$, SUN Wei (孙卫) $)^{3}$, MIAO Jianyu (苗建宇) $)^{3}$, and LIU Chiyang (刘池阳) ${ }^{3}$

${ }^{1}$ CAS Key Laboratory of Crust-Mantle Materials and Environments, School of Earth and Space Sciences, University of Science and Technology of China, Hefei 230026, China

${ }^{2}$ Research Center of Oil and Natural Gases, University of Science and Technology of China, Hefei 230026, China

${ }^{3}$ Department of Geology, Northwest University, Xi'an 710069, China

Erratum: Chin. J. of Geochem.

DOI: 10.1007/s11631-006-0354-y

Table 3 on page 360 is incorrect and should be replaced by the table below.

Table 3. The results of analysis of trace elements for the sandstone-type uranium deposit samples from the Ordos Basin $(\mu \mathrm{g} / \mathrm{g})$

\begin{tabular}{|c|c|c|c|c|c|c|c|c|c|c|c|c|c|c|c|c|c|c|c|c|c|}
\hline Sample No. & $\mathrm{Rb}$ & Th & U & $\mathrm{Ta}$ & $\mathrm{Nb}$ & $\mathrm{La}$ & $\mathrm{Ce}$ & $\mathrm{Pb}$ & Pr & $\mathrm{Sr}$ & $\mathrm{Nd}$ & $\mathrm{Hf}$ & $\mathrm{Zr}$ & $\mathrm{Sm}$ & $\mathrm{Eu}$ & $\mathrm{Gd}$ & Dy & Y & $\mathrm{Er}$ & $\mathrm{Yb}$ & $\mathrm{Lu}$ \\
\hline GSR-4 & 27.6 & 7.05 & 2.00 & 0.35 & 5.90 & 28.5 & 48.1 & 7.08 & 6.34 & 53.18 & 23.9 & 1.82 & 73.1 & 5.58 & 1.00 & 4.70 & 3.84 & 18.4 & 2.09 & 1.81 & 0.23 \\
\hline GSR-5 & 219 & 18.95 & 1.78 & 1.13 & 19.3 & 59.8 & 100.7 & 9.31 & 12.8 & 123.07 & 44.2 & 3.18 & 123 & 8.01 & 1.73 & 6.52 & 6.01 & 38.9 & 3.78 & 3.54 & 0.45 \\
\hline ZK183-79-02 & 89.8 & 8.14 & 2.05 & 0.61 & 8.80 & 38.8 & 63.6 & 13.8 & 7.69 & 347.77 & 26.2 & 1.38 & 49.1 & 4.30 & 2.06 & 3.64 & 2.42 & 11.4 & 1.35 & 1.14 & 0.15 \\
\hline ZK183-79-06 & 82.0 & 3.12 & 0.92 & 0.41 & 5.44 & 21.4 & 33.0 & 10.9 & 4.26 & 378.50 & 15.4 & 3.89 & 92.3 & 2.90 & 2.00 & 2.47 & 1.99 & 10.2 & 1.13 & 0.94 & 0.13 \\
\hline ZK183-79-09 & 74.7 & 5.07 & 5.73 & 1.02 & 13.63 & 36.5 & 53.1 & 20.5 & 8.31 & 325.86 & 31.4 & 2.14 & 85.5 & 6.51 & 2.33 & 5.50 & 5.67 & 28.0 & 3.44 & 3.24 & 0.41 \\
\hline ZK183-79-12 & 68.8 & 2.74 & 34.4 & 0.50 & 6.60 & 19.8 & 21.7 & 11.2 & 4.03 & 284.65 & 14.2 & 1.52 & 58.8 & 2.47 & 1.67 & 2.16 & 1.90 & 8.84 & 1.19 & 1.19 & 0.15 \\
\hline ZK341-60-04 & 76.5 & 2.34 & 0.73 & 0.51 & 8.09 & 19.9 & 25.8 & 13.8 & 3.85 & 212.14 & 13.3 & 3.55 & 96.3 & 2.38 & 1.95 & 2.00 & 1.48 & 6.23 & 0.85 & 0.83 & 0.11 \\
\hline ZK341-60-05 & 106 & 22.94 & 4.35 & 1.39 & 23.9 & 104 & 153 & 31.9 & 21.1 & 188.97 & 73.0 & 4.58 & 173 & 11.85 & 2.72 & 10.26 & 9.08 & 44.7 & 5.60 & 5.29 & 0.67 \\
\hline ZK64-127-S-07 & 138 & 7.54 & 3.13 & 0.65 & 11.2 & 40.8 & 62.8 & 17.6 & 8.93 & 147.61 & 32.1 & 2.33 & 82.4 & 5.27 & 1.49 & 3.58 & 2.04 & 9.64 & 1.32 & 1.39 & 0.19 \\
\hline ZKA139-35-03 & 100 & 5.50 & 0.73 & 0.63 & 11.3 & 25.6 & 32.9 & 15.1 & 5.52 & 422.43 & 20.5 & 1.49 & 57.2 & 4.17 & 1.86 & 4.01 & 4.53 & 37.0 & 3.30 & 3.16 & 0.40 \\
\hline ZKA139-35-05 & 56.7 & 16.37 & 90.4 & 2.25 & 43.2 & 68.7 & 99.2 & 21.7 & 13.98 & 264.51 & 46.1 & 4.47 & 180 & 7.28 & 1.71 & 6.49 & 5.95 & 26.8 & 4.08 & 3.89 & 0.49 \\
\hline ZKA139-35-13 & 73.1 & 3.50 & 8.68 & 0.87 & 14.0 & 17.4 & 23.4 & 14.5 & 3.80 & 309.32 & 13.2 & 2.70 & 76.6 & 2.37 & 1.51 & 2.33 & 2.12 & 9.63 & 1.41 & 1.38 & 0.17 \\
\hline ZKA183-87-02 & 115 & 11.46 & 2.30 & 1.32 & 21.5 & 62.0 & 94.2 & 23.9 & 13.01 & 325.85 & 44.2 & 3.23 & 132 & 6.63 & 1.88 & 6.20 & 5.24 & 32.4 & 3.34 & 3.11 & 0.38 \\
\hline ZKA183-87-08 & 93.9 & 4.81 & 81.1 & 0.50 & 12.1 & 41.1 & 44.4 & 10.5 & 7.31 & 277.70 & 23.2 & 1.74 & 82.2 & 4.09 & 1.61 & 3.74 & 3.28 & 18.2 & 1.99 & 1.77 & 0.23 \\
\hline ZKA183-87-09 & 108 & 6.86 & 150 & 1.11 & 21.1 & 29.3 & 44.3 & 22.1 & 6.49 & 321.87 & 22.6 & 3.26 & 152 & 3.97 & 1.52 & 3.30 & 2.86 & 16.2 & 1.98 & 1.97 & 0.26 \\
\hline ZKA183-87-10 & 66.5 & 67.75 & 58.1 & 3.30 & 96.3 & 176.4 & 249.9 & 25.3 & 33.39 & 261.11 & 107.6 & 24.07 & & 16.17 & 2.02 & 14.81 & 11.03 & 69.3 & 7.30 & 7.05 & 0.96 \\
\hline ZKA39-14-02 & 112 & 17.17 & 3.35 & 1.74 & 20.84 & 61.3 & 106.5 & 23.9 & 11.80 & 313.23 & 41.0 & 7.90 & 215.1 & 7.08 & 1.62 & 5.95 & 5.07 & 31.2 & 2.93 & 2.71 & 0.35 \\
\hline ZKA39-14-04 & 63.9 & 2.78 & 3.16 & 0.62 & 5.58 & 41.3 & 53.3 & 16.6 & 7.76 & 280.73 & 27.3 & 1.64 & 49.1 & 4.71 & 1.89 & 3.84 & 3.30 & 12.0 & 2.18 & 2.17 & 0.29 \\
\hline ZKA39-14-06 & 42.5 & 3.56 & 32.2 & 0.63 & 11.64 & 11.2 & 11.6 & 10.5 & 2.59 & 229.50 & 9.31 & 1.70 & 58.4 & 1.70 & 0.89 & 1.33 & 1.35 & 6.45 & 0.90 & 1.04 & 0.14 \\
\hline ZKA79-11-05 & 111 & 17.56 & 2.00 & 1.19 & 21.14 & 41.9 & 75.6 & 28.7 & 9.31 & 379.13 & 33.4 & 3.19 & 112.3 & 6.16 & 1.52 & 5.06 & 4.79 & 33.6 & 2.94 & 2.88 & 0.39 \\
\hline ZKA79-11-09 & 67.3 & 4.37 & 108 & 0.52 & 10.10 & 27.7 & 31.8 & 18.0 & 5.58 & 305.24 & 19.4 & 3.05 & 74.0 & 3.55 & 1.45 & 2.87 & 2.93 & 13.2 & 1.84 & 1.79 & 0.24 \\
\hline ZKA79-11-11 & 64.9 & 2.63 & 69.5 & 0.47 & 9.03 & 8.77 & 8.96 & 8.94 & 1.67 & 251.21 & 5.88 & 2.13 & 61.2 & 1.14 & 1.01 & 0.97 & 0.95 & 5.31 & 0.69 & 0.71 & 0.10 \\
\hline ZKA79-11-12 & 77.0 & 4.39 & 71.3 & 0.77 & 13.03 & 28.6 & 41.8 & 14.7 & 5.49 & 284.27 & 19.1 & 1.85 & 72.8 & 3.47 & 1.52 & 2.72 & 2.36 & 9.63 & 1.57 & 1.64 & 0.25 \\
\hline
\end{tabular}

